\title{
A história não ensinada sobre a ditadura civil-militar: reflexões sobre pesquisa e ensino no contexto amapaense
}

\author{
The history not taught about the civil-military Dictatorship: \\ reflections on research and teaching in Amapá State context
}

\author{
Júlia Monnerat Barbosa* \\ Maura Leal da Silva**
}

\begin{abstract}
RESUMO: Este texto parte de nossas experiências como professoras de História (primeiro da educação básica e depois da educação superior), como membros do colegiado da Comissão Estadual da Verdade do Amapá (CEV-AP) e como pesquisadoras do Grupo de Pesquisa Democracias e Ditaduras da Unifap. Seu objetivo principal é compreender o papel que o ensino de História pode e deve exercer dentro de um contexto mais amplo de políticas públicas voltadas para a manutenção da democracia. Metodologicamente escolhemos fazer essa discussão a partir de dois balanços: na produção historiográfica sobre o tema da Ditadura Civil-Militar amapaense e nas potencialidades das pesquisas desenvolvidas pela Comissão Estadual da Verdade do Estado do Amapá para o ensino de História. Ambos os caminhos convergem à constatação de que a pouca produção existente sobre esse tema localmente e o fato de as informações levantadas pela CEV-AP ainda permanecerem em circulação restrita dificultam bastante as possibilidades de desenvolvimento mais aprofundado da temática na educação básica. Este artigo pretende servir como um balanço de fontes (primárias e secundárias) como forma de subsidiar professores e professoras de História nas escolas do Amapá a pensar a Ditadura a partir de personagens, temáticas e processos próprios. Palavras-chave: Ensino de História. Ditadura. Comissão da Verdade. História Local.
\end{abstract}

ABSTRACT: The current text comes from our experiences as History teachers (first in elementary, than in higher education), as members of the organization Truth Commission from Amapa State (CEV-AP) and as researchers from the Research Group about Democracies and Dictatorships at UNIFAP. Its main goal is to understand the role that the History teaching may and must play inside a wider context of public policies directed to the maintenance of democracy. Methodologically we have chosen to start the discussion as of two statements: the historiographic production about the

\footnotetext{
* Professora Adjunta de Metodologia Ensino de História da Universidade Federal do Amapá, Júlia é feminista e pensa o mundo a partir da identificação de sistemas de opressão e das possibilidades de resistência. Dessa maneira, pesquisou Movimentos Grevistas no Rio de Janeiro entre 1945 e 1954 (para obtenção do título de Mestre em História pela UERJ), a relação entre produção literária e a militância no Partido Comunista nas trajetórias de Jorge Amado e Graciliano Ramos (para a obtenção do título de Doutora em História pela UFF), fez parte da Comissão Estadual da Verdade do Amapá e atualmente faz parte do Grupo de Pesquisa Democracias e Ditaduras da UNIFAP, onde desenvolve pesquisas sobre História das Mulheres, das Relações de Gênero e da Sexualidade e da Ditadura Civil-Militar, sobretudo a partir de questões relacionadas ao ensino de História.

** Mãe da Laura, feminista, professora Adjunta de História do Brasil da Universidade Federal do Amapá, desde 2013. Graduada em História pela mesma instituição (1994). Mestre em História pela PUC/SP (2007) e Doutora em História Pela UnB (2017). Atuou como professora da Educação Básica na Rede Pública do Estado do Amapá, entre os anos de 1994 e 2013. Foi membro do Colegiado da Comissão Estadual da Verdade do Amapá, de 2013 a 2017. Atualmente coordena o Grupo de Pesquisa Democracias e Ditaduras da UNIFAP, onde desenvolve pesquisas nas áreas do Brasil República, com ênfase em estudos regionais e locais, nos temas Ditadura Civil-Militar na Amazônia e Amapá e no ensino de História da Ditadura.
} 
topic civil-military dictatorship in Amapá and the potentialities of research developed by the Truth Commission from Amapá State for History teaching. Both tracks lead to the same ascertainment that the little local existing production about the topic and the fact that the information collected by CEV-AP still remains in restrict circulation make it more difficult to develop the topic more deeply in elementary education. This article aims to serve as balance of sources (primary and secondary) as a way to help History teachers in schools in Amapá to reflect on the Dictatorship as of characters, themes, and its own processes.

Keywords: History teaching. Dictatorship. Truth Commission. Local History.

\section{Considerações iniciais}

O processo eleitoral de 2018 nos colocou diante de um retrato do Brasil que revelou muito da sociedade brasileira, sobretudo aquela face que banaliza o mal, como nos leva a refletir Hannah Arendt (1999). Dentre as feridas expostas nesse processo, ficou claro para nós que parcela significativa de nossa sociedade acolhe declarações favoráveis a regimes autoritários e à apologia à tortura (sem falar da explicitação do racismo, da misoginia, da lgbtfobia e de vários ódios de classe, raça e gênero subjacentes a um tecido social profundamente desigual). Como professoras de licenciatura em História e pesquisadoras da Ditadura Civil-Militar, a sala de aula nunca esteve tão pulsante. Entre os muitos momentos difíceis desse período, partilhados nessa parceria que ultrapassa a escrita deste artigo e o nosso oficio, a visão de um aluno jovem do primeiro semestre de graduação em História, vestindo uma camiseta com a imagem de Bolsonaro, defendendo em sala de aula a Ditadura Civil-Militar brasileira e relativizando a tortura à que a presidenta Dilma Rousseff foi submetida, já que a acusava de ter praticado terrorismo contra o Estado, foi talvez um dos mais desanimadores, pois nada é mais perturbador do que o sentimento de que, como sociedade, não fizemos corretamente o dever de casa.

Nossa pretensão a é de contribuir com esse debate através de reflexões acerca do ensino de História da Ditadura Civil-Militar, direcionando tais proposições a profissionais da educação que desejem encarar esse desafio de refletir sobre a necessidade de uma educação voltada para a democracia e do papel que desempenham nesse processo. Nesse ínterim, pensar práticas pedagógicas que ofereçam análises históricas sobre a Ditadura pressupõe a existência de material de pesquisa que possa ser acessado por quem se propõe a levar a temática para a sala de aula.

Como professoras do curso de licenciatura em História da Universidade Federal do Amapá, temos nos preocupado com as possibilidades de entender a Ditadura como um momento histórico que foi marcado por características gerais as quais se manifestaram em todo o território nacional e, para isso, devemos nos comprometer com uma pesquisa e um ensino que permitam uma leitura mais completa da sociedade brasileira. Para ultrapassar as generalizações sobre a Ditadura, é necessário que se amplie o entendimento da heterogeneidade desse país de proporções continentais e de estudos sobre como ela operou em territórios não explorados pela pesquisa histórica, a exemplo na região Norte, no Amapá. Portanto, trabalhamos através da investigação das pesquisas científicas produzidas sobre o período ditatorial no Amapá, principalmente a partir das possibilidades abertas para o ensino de História, visando a entender o papel do ensino dentro de um contexto mais amplo de políticas públicas e transacionais ${ }^{1}$ como caminho para uma educação que estimule o exercício

\footnotetext{
${ }^{1} 0$ termo transacional está diretamente relacionado ao que se compreende por "justiça de transição" e se refere a todas as medidas tomadas no processo de transição de regimes autoritários para regimes democráticos. Sobre isso, ver Tosi (2014).
} 
democrático, a garantia de direitos e o respeito à vida como bem maior.

Queremos chamar atenção para dois aspectos da percepção social sobre a temática em questão que consideramos relevantes para essa discussão. O primeiro é a compreensão de que uma parcela considerável da sociedade brasileira, em especial os mais jovens, desconhece ou não reconhece esse período recente como uma experiência autoritária. O segundo é a defesa de que, para uma boa percepção da nossa realidade (e da história do Brasil recente), o professor e a professora de História não poderão se furtar ao enfrentamento, em sala de aula, dessa temática. Acreditamos ser, principalmente, a partir da inclusão da experiência da Ditadura nas aulas de História da educação básica que poderemos contribuir para que as novas gerações consigam construir o conhecimento/reconhecimento das experiências autoritárias vivenciadas no país (em períodos de exceções ou em governos democráticos) como alicerces estruturantes de nossa instabilidade democrática, mesmo tendo em mente que esse processo educacional não depende somente das aulas de História.

Nunca é demais lembrarmo-nos de que conhecer a verdade e ter acesso à história é um direito de todas as pessoas, pois, como bem defende Paulo Abrão (2013), ofertar, através da educação, o conhecimento desse passado autoritário, o qual ainda condiciona nosso presente, é certamente um ato político. Portanto, se tivermos como princípio o compromisso com a democracia, é necessário que se faça chegar aos mais jovens o conhecimento dos erros cometidos no passado para que eles próprios não sejam vetores de repetição no futuro (ABRÃO, 2013). Entretanto, nossa premissa é a de que essa tarefa de rememoração e de construção de um ensino de História, referenciado na expansão do conhecimento de mundo e da realidade social, é dificultada pela inexistência de políticas educacionais comprometidas com o entendimento e com a divulgação do que essa experiência autoritária significou e significa.

Portanto, a centralidade que damos para o papel do ensino neste texto não está ancorada nos esforços individuais que professoras e professores já vêm fazendo, ao longo dos anos, no sentido de apresentar em salas de aula (e dentro dos parâmetros científicos) o que a Ditadura representou para a configuração de nossa realidade social. Não compartilhamos dessa visão que responsabiliza individualmente professores e professoras de História sobre os rumos de nossa sociedade no presente. Nossa afirmação no título deste artigo de que a Ditadura é uma temática não ensinada não visa a chamar atenção para o aspecto individual do exercício da docência, mas para um compromisso coletivo, pois defendemos que só através da responsabilização por instituições do Estado de ofertar a formação inicial e continuada de professoras e professores, de desenvolver projetos de pesquisa e de ensino, de garantir o acesso a material de pesquisa e para o ensino é que poderemos combater o ocultamento de diversas temáticas (e sujeitos) no ensino de História.

Nesse sentido, a proposta deste artigo é fazer um balanço das dificuldades enfrentadas para se trabalhar com a temática da Ditadura Civil-Militar a partir das reflexões sobre a realidade amapaense, na qual nos situamos. Escolhemos fazer essa reflexão por dois caminhos que se interligam nessa análise. O primeiro é traçado a partir de um levantamento preliminar de artigos, dissertações e teses sobre a Ditadura Civil-Militar já publicados e defendidos, para que assim se possa verificar o que já se tem escrito sobre esse período. O segundo é trilhado a partir de reflexões sobre as potencialidades das pesquisas desenvolvidas pela Comissão Estadual da Verdade do Amapá (CEV$\mathrm{AP})^{2}$ para o ensino de História. Ambos os caminhos convergem para uma constatação: trabalhar

2 A Comissão Estadual da Verdade do Amapá foi criada por iniciativa do Governo do Estado do Amapá, em 24 de junho de 2013, e teve suas atividades encerradas em junho de 2017. Foi a primeira Comissão da Verdade criada na Amazônia, objetivando, assim como as demais comissões, oferecer subsídios aos trabalhos realizados pela Comissão Nacional da Verdade (CNV), bem como contribuir para elucidação das 
com a Ditadura em sala de aula, a partir da experiência amapaense, não é fácil. A pequena produção existente sobre esse tema localmente, bem como o fato de as informações levantadas pela Comissão Estadual da Verdade do Amapá ainda permanecerem em circulação restrita, indicam a necessidade de publicização e circulação de fontes primárias e secundárias sobre a temática.

Dada a urgência dessa discussão e a necessidade de enfrentamento do tema nas escolas, na universidade e nos espaços de construção de uma história pública ${ }^{3}$, é que esperamos de alguma forma contribuir com esse processo de sistematização e de divulgação de dados que possam auxiliar professoras e professores de História nas escolas do Amapá a trabalharem com essa temática, reportando-se também à realidade local, como forma de auxiliá-los na seleção de conteúdo, na elaboração de planos de aula, de material didático e demais instrumentos de ensino.

\section{Pesquisa e ensino da Ditadura: a produção historiográfica local e as possibilidades abertas para o ensino}

Em um levantamento preliminar de artigos publicados em anais de eventos e revistas especializadas da área de História e nos bancos de dissertações e teses defendidas que possuem como delimitação espacial o Amapá, pode-se afirmar que o tema da Ditadura Civil-Militar é pouquíssimo estudado. Como critérios de seleção, ativemo-nos a pesquisas desenvolvidas na área de História que possuem como tema central a Ditadura ${ }^{4}$ Palavras-chaves como "Ditadura", "Amapá", "Macapá" e algumas variações como "amapaense" e "macapaense" foram utilizadas para auxiliar na seleção. Como a Unifap é a única instituição de ensino que oferta cursos de pós-graduação stricto sensu em História no Estado do Amapá, fizemos também uma seleção partindo de pesquisas desenvolvidas por docentes e (ex) discentes dessas pós-graduações. Durante o período em que estivemos na Comissão Estadual da Verdade do Amapá, para subsidiar nosso trabalho, realizamos um levantamento semelhante e, agora, passados três anos da publicização do relatório final dessa comissão, achamos interessante uma retomada desse balanço, passando à apresentação dessas publicações para, em seguida, tecer algumas reflexões sobre a produção historiográfica sobre o tema no Amapá.

Os trabalhos da Comissão Estadual da Verdade do Amapá e os esforços que têm sido desenvolvidos nos últimos dez anos dentro na Unifap parecem contribuir para um aumento da produção na área ${ }^{5}$. Até a finalização dos trabalhos da CEV-AP era possível localizar na área da

violações aos direitos humanos cometidas em Território Federal do Amapá (atual Estado do Amapá) durante a Ditadura Civil-Militar no Brasil.

${ }^{3}$ A história pública pode ser compreendida de formas diferentes nos países que a praticam. Seu uso teria sido empregado pela primeira vez nos Estados Unidos, em 1976, pelo historiador Robert Kelley, fundador da revista The Publican Historian, que a descreveu como um conjunto de procedimentos voltados para um conhecimento histórico que ultrapasse os muros da universidade. No Brasil, os debates sobre ela teriam ganhado força em 2011, durante o Curso de Introdução à História Pública, oferecido pela USP. Seu uso vem crescendo no Brasil, sobretudo após a expansão da História Oral e da História do Tempo Presente, e não há como não relacionar seu crescimento à defesa de uma História cada vez mais impactada pelas disputas por direitos a políticas públicas, de memória e de reparação. Ver: Mauad (2016).

4 Algumas pesquisas na História e áreas afins já abordaram esse período no Amapá, mas a Ditadura não aparece nesses estudos como tema central, por isso elas não foram citadas neste artigo

${ }^{5}$ Analisando as pesquisas em andamento em nível de mestrado é possível vislumbrar um cenário bastante animador. Marcella Viana, no Programa de Pós-Graduação em História da UnB, vem dando continuidade à pesquisa que desenvolveu na graduação sobre o movimento estudantil amapaense na época da Ditadura, a partir de uma perspectiva bastante interessante, que considera segmentos desse movimento pouco pesquisado até o presente, como o secundarista 5 . Higor Pereira, mestrando do Programa de Pós- 
História apenas a dissertação de mestrado Ditadura Militar no Amapá: terror, resistência e subordinação ${ }^{6}$, de Dorival Santos da Costa, defendida em 2001, pela UNICAMP. Foi só após a finalização dos trabalhos na presidência da CEV-AP, em 2017, que Santos a publicou em formato de livro impresso, com o título Entre a Tortura e a Matinta Pereira: uma abordagem cultural da ditadura no Amapá. Um ano após a publicação do relatório final da CEV-AP surgiu a dissertação de mestrado Tempo de lembrar: memórias da ditadura e ensino de história do Amapá, defendida em 2018, por Danilo Pacheco, no programa de Mestrado Profissional em História da Unifap, abordando especificamente o ensino da Ditadura Civil-Militar através do uso dos testemunhos da CEV-AP na educação básica.

Em relação à publicação de artigos em anais, revistas e livros que tratem especificamente da Ditadura a partir da realidade amapaense, seguindo uma ordem cronológica por datas de publicação, pode-se citar os artigos de autoria de Maura Leal da Silva. O primeiro deles, em 2014, com o título: "O Território do Terror: agitações, prisões e repressões no alvorecer do Golpe Civil Militar no Amapá”, publicado nos Anais do "Seminário 1964-2014: um olhar crítico, para não esquecer". O segundo, em 2015, intitulado “A Ditadura da liberdade. Um Brasil que 64 não revelou”, publicado nos Anais do "XXVII Simpósio Nacional de História (ANPUH)". Ambos os artigos chamam atenção para existência de práticas autoritárias promovidas pelo aparelho estatal, como censura e privações de liberdade, presentes no cotidiano da sociedade amapaense em momentos anteriores a 1964, as quais, como indica a autora, merecem ser ainda mais investigadas.

Walbi Silva Pimentel, quando mestrando do ProfHistória, escreveu "A Igreja dos Pobres no Amapá: solidariedade, resistência e conflito (1966- 1983)”, publicado em 2017, nos Anais do “III Encontro de Discentes de História da UNIFAP”. Nesse artigo, Pimentel buscou pontuar como se constituíram as CEBs no Amapá, com recorte em um dos bairros de Macapá, o Buritizal. Utilizando-se do jornal $A$ Voz Católica e de entrevistas, seu objetivo foi analisar o papel das CEBs e identificar possíveis "enfrentamentos" entre Igreja e Estado decorrentes da prática pastoral dessas comunidades.

Giovani José da Silva e Anderson Luis Azevedo da Rocha, em 2019, publicaram na revista História Unicap o artigo intitulado "História, ambiente e povos indígenas no extremo Norte do Brasil: impactos da construção da BR-156 em Oiapoque, Amapá (1976-1981)”, no qual analisam, em relação à construção da rodovia BR-156, as mobilizações dos povos Palikur, Karipuna e Galibi Marworno do Oiapoque, no sentido de proteção de seus territórios, em embates com os agentes do Estado no período da Ditadura Civil-Militar, entre os anos de 1976 e 1981. Fazendo uso do conceito de conflito socioambiental, definido pela Antropologia como disputas entre grupos sociais que se relacionam de diferentes maneiras com o meio natural, os atores tratam de uma temática importantíssima, ainda não inquirida com a devida atenção dentro dos estudos sobre a Ditadura na região com relação às populações indígenas.

Outro autor que identificamos entre as produções recentes do Amapá sobre o tema é Sidney Lobato. No artigo "O Espetáculo da Ordem: paradas estudantis amapaenses em tempos de ditadura (1967-1972)”, publicado em 2018, o autor analisa o papel dos desfiles cívicos estudantis

Graduação em História (PPGH) da Unifap, vem pesquisando os conflitos de terra no Amapá, com a instalação da empresa Amcel, com o objetivo de entender a Ditadura no Amapá a partir da aliança empresarialmilitar, conforme a expressão desenvolvida por René Dreifuss (1981). É uma perspectiva promissora sobre o tema não só em nível local, mas nacional também, por envolver sujeitos inviabilizados pela historiografia do período (os camponeses).

${ }^{6}$ Antes da publicação da dissertação em livro, Santos escreveu, em 2011, um artigo resumido da sua pesquisa de mestrado na coletânea do Do Lado de Cá: fragmentos de História do Amapá, com o título "Entre masmorras reais e imaginárias vicejou o terror: a violência do estado durante a ditadura militar no Amapá”. 
realizadas durante o governo de Ivanhoé Martins como forma de controle social do regime. Já em "Os Empresários e a Amazônia: planejamento regional e protagonismo empresarial no início da ditadura militar (1964-1966)", texto recém-lançado, em 2020, Lobato discute a exploração capitalista na região amapaense pela Operação Amazônia de 1966. Ambas as publicações são capítulos de livros, frutos de pesquisas iniciais ou em andamento e, como o próprio autor enfatiza nas conclusões dos dois artigos, precisando ainda de aprofundamento.

Esse levantamento chama a atenção para a escassez de materiais sobre a temática, fazendo com que cada pesquisa apresentada em forma de artigo ou de dissertação compartilhe do ineditismo, o que confirma a pouca incidência de pesquisas sobre a Ditadura na região. Uma explicação para essa baixa expressividade, assim como a de outros temas, pode estar relacionada ao fato de a graduação em História da Universidade Federal do Amapá (Unifap) ser relativamente jovem se comparada a de outros estados ${ }^{7}$. Sua origem só ocorreu em 1991, no processo de transição de Território Federal para Estado. Somente em 2015 a Unifap passou a integrar a Rede Nacional do Mestrado Profissional em Ensino de História (ProfHistória) e só recentemente, em 2018, conseguiu implantar seu curso de Mestrado Acadêmico em História.

Não cabe aqui uma reflexão sobre os outros espaços em que se forjam socialmente entendimentos sobre o último período ditatorial na história do Brasil, como redes sociais, mídias eletrônicas, aplicativos de comunicação etc. Todavia, é necessário destacar que essa pequena produção historiográfica e os silêncios sobre o período nos espaços de pesquisa e ensino - sejam eles escolas ou universidades - acabam por reforçar no imaginário social amapaense aspectos que condicionam a maneira de se olhar para esse período, por exemplo, a compreensão socialmente partilhada de que a Ditadura teria se processado a nível local de maneira muito mais branda do que no restante do país, uma vez que Macapá não vivenciou a intensidade de prisões, torturas e mortes de cidades como São Paulo, Rio de Janeiro e Belo Horizonte.

Também aparece com frequência no imaginário social sobre a temática a ideia de que a Ditadura nem sequer teria existido na região. Essa visão é reforçada pelo argumento de que, se não houve mortes e desaparecimentos, não houve, portanto, Ditadura. Não é porque não se tem registros oficiais de mortos e desaparecidos vítimas da Ditadura no Amapá até o presente (excetuados os casos dos soldados Cabral e Ovídio ${ }^{8}$, que morreram por ocasião das operações contra militantes da resistência na Guerrilha do Araguaia), que se possa afirmar que crimes de tortura e assassinato não ocorreram de maneira muito mais volumosa na região do que o indicado no relatório da CEVAP. Isso acaba por sinalizar para a necessidade de realização de pesquisas sobre Ditadura no Amapá para que esse e outros aspectos ainda não devidamente esclarecidos possam ser melhor evidenciados.

Novas pesquisas sobre a temática ajudariam a confrontar a negação de que no Amapá não houve um regime autoritário - como se fosse possível mensurar pela quantidade de mortos e

\footnotetext{
${ }^{7}$ Como São Paulo e Rio de Janeiro, por exemplo, estados onde os primeiros cursos de graduação em História datam da década de 30 do século passado.

8 Conforme o depoimento de Raimundo José da Silva Rodrigues à CEV-AP, que prestou serviço ao Exército brasileiro na Guerrilha do Araguaia, entre os anos de 1972-1973, as mortes de Ovídio e Cabral ocorreram por engano, vítimas do "fogo amigo". Cabral foi confundido com um guerrilheiro e, por não proferir a senha da guarnição, seu companheiro, o cabo Nobre, acabou efetuando o disparo que o matou, em 1972. Já Ovídio teria sido alvejado, em 1973, por um outro soldado, quando retornava para o acampamento, após uma inspeção em busca de alimentos, em uma região insalubre, com pouca luminosidade, de mata fechada e de difícil acesso. As circunstâncias da morte de Ovídio e Cabral não foram, à época e nem até o presente, devidamente esclarecidas pelo Exército.
} 
desaparecidos a violência cometida por agentes da repressão e mascarar a gravidade de torturas e crimes que ainda ecoam no presente e que são em parte incentivados por essa naturalização da violência praticada por agentes de Estado. Se formos analisar os números da violência cometida pelo Estado, fica evidente como essa percepção é preocupante. No primeiro semestre de 2020, mesmo com isolamento social, o Brasil registrou em plena pandemia um acréscimo da letalidade policial, com um aumento de 7\% em relação ao mesmo período de 2019, e o Amapá foi o estado que apresentou a maior taxa de mortes por policiais, 8,1, por 100 mil habitantes do período?.

A forma saudosista de se enxergar a Ditadura, aqui apontada a partir da experiência particular do Amapá, não é nenhuma novidade no Brasil. Desde o princípio da transição democrática nos "embates de memórias" sobre a Ditadura, sempre existiram aqueles que reivindicam uma memória positiva do período, que não negam a existência da Ditadura em sua totalidade, mas que buscam amenizar seus efeitos. Porém, conforme Caroline Bauer (2020), a partir de 2010 ocorreu uma mudança substancial nos sentidos e nos usos políticos do passado da Ditadura Civil-Militar brasileira, caracterizado pela crise cultural, econômica, política e social, e elaborada com base na crítica à democracia representativa que relativiza as condenações ao autoritarismo e a regimes antidemocráticos "que implicaram na formulação de uma forma particular de relato memorial sobre a ditadura" (BAUER, 2020, p. 228).

Para Bauer, o negacionismo é um fenômeno social que transcende os debates intelectuais, mas que apresenta no Brasil suas especificidades, pois é um discurso que não só se alimenta e se nutre de conjunturas de crise, como "caracteriza-se por uma retórica marcada por distorções e idealismo, que não necessariamente negam ou revisam a ditadura, mas que procuram legitimar e justificar suas práticas [...]” (BAUER, 2020, p. 229). Infelizmente não é possível um maior aprofundamento da questão levantada por Bauer no que se refere às particularidades desse negacionismo no Amapá, mas pode-se afirmar que, dado em grande parte ao processo de formação recente do estado $^{10}$, o negacionismo foi retórica política dos governos militares que tentavam disseminar entre a população a defesa de que se vivia tempos áureos na região em razão dos investimentos públicos federais enviados no período do Amapá federal, quando a região esteve sob a tutela da União.

Fazendo-se as devidas ponderações, os estudos sobre a Ditadura na região nasceram sob esse estigma negacionista. Enquanto em nível nacional houve, desde sempre, uma tentativa de minimizar as torturas e os assassinatos pelo Estado, comparando nossa Ditadura a realidades como a da Argentina (onde as mortes e desaparecimentos de que se têm registro são superiores aos do Brasil), em nível local a comparação se estabelece como forma de abrandar ainda mais a Ditadura brasileira e até mesmo de negar sua existência. No depoimento de João Cardoso Neto, ex-agente de polícia que chegou a trabalhar como escrivão substituto no DOPS em Macapá, essa forma de enxergar a Ditadura local como mais branda do que a nacional é explícita: "[..] sempre digo que de todo o Brasil onde a revolução menos operou foi no Amapá. [...] Esse problema do Araguaia que viram desaparecer com as pessoas, pau-de-arara, choque elétrico de Belém para lá. Eu garanto para vocês que aqui não (NETO CARDOSO, 2014, s/p).

É importante destacar que, assim como a Ditadura não foi sentida da mesma maneira pelos diversos setores da sociedade brasileira, sua abrangência também foi experienciada de diferentes

9 O levantamento faz parte do Monitor da Violência, uma parceria do G1 com o Núcleo de Estudos da Violência da USP e o Fórum Brasileiro de Segurança Pública. Disponivel em: ttps://g1.globo.com/monitor-da-violencia/noticia/2020/09/03/no-de-pessoas-mortas-pela-policia-cresce-no-brasil-no-10-semestre-em-plena-pandemia-assassinatos-de-policiais-tambem-sobem.ghtml. Acesso em: 26 set. 2020.

10 Ver Silva (2017) 
formas pelos habitantes das diversas cidades do país. Da mesma forma, se em alguns aspectos a Ditadura foi explícita, em outros ela encontrou maneiras de mascarar a realidade, a ponto de dificultar o reconhecimento de determinadas práticas autoritárias. Talvez aqui resida uma reflexão pouco explorada sobre as diversas faces da Ditadura brasileira suscitada a partir da experiência amapaense. A dificuldade de reconhecer que houve Ditadura no Amapá pode ser explicada pela forma como se interpreta o período e como se lida com a sua memória. Para Carlos Fico (2020, p. 1390), "a sociedade brasileira ainda não conhece em detalhes a violência que se praticou durante os governos militares”. Temas como prisões arbitrárias, torturas, mortes e repressão são os mais conhecidos, porém "muita gente teve sua vida afetada pelo regime, não necessariamente pela violência física, mas de muitas outras formas, como sempre ocorre em qualquer regime de restrição de liberdade" (FICO, 2020, p.139).

Fico (2020) toca em um aspecto fundamental sobre os estudos da Ditadura e, a partir dele, traçamos um paralelo com o ensino. O conhecimento histórico cumpre certamente um papel importante, "mas o alcance da pesquisa histórica é muito limitado" (FICO, 2020, p.250). Infelizmente, existe um abismo gigantesco entre o que se produz nas universidades e o conhecimento histórico se se produz nas escolas. O tema da Ditadura, talvez, seja um dos mais afetados pelo pouco diálogo entre as diversas instâncias de ensino e pesquisa. Sobretudo, porque temas de natureza "sensível" (ARAÚJO, 2013), como os que envolvem processos marcados pelo autoritarismo de Estado e pela violência traumática, até recentemente eram vistos como tabus ou de difícil abordagem.

Muito embora haja um esforço no sentido de se estudar como a região Norte também foi atingida pela Ditadura, assim como nas demais regiões brasileiras, as pesquisas e políticas transicionais se concentram quase que exclusivamente no eixo Sul-Sudeste. Do ponto de vista da pesquisa histórica, se pensarmos no volume de estudos (teses, dissertações e artigos científicos que apresentamos), pouco se sabe sobre como a Ditadura atuou nessa região. Isso faz com que o acesso ao trabalho desempenhado pela comissão do Amapá seja bastante necessário, sobretudo em um estado sem arquivo público e com problemas sérios de acesso à documentação histórica.

\section{O acesso à História como direito universal: o ensino de História pen- sado a partir da Comissão Estadual da Verdade do Amapá}

O acesso à documentação colhida e produzida pela Comissão Estadual da Verdade do Amapá nos parece ser um dos caminhos para o desenvolvimento e acúmulo de pesquisas sobre a temática, voltadas ou não para a área do ensino de História. É importante destacar que a criação da CEV-AP fez parte de um longo processo global de busca pelo direito à memória, verdade e justiça. Como último país da América Latina a instituir um mecanismo oficialmente reconhecido para investigar, esclarecer e reconhecer formalmente os abusos do passado, o Brasil promulgou a Lei 12.528, de 18 de novembro de 2011 (BRASIL, 2011), que criou a Comissão Nacional da Verdade (CNV). Sua criação só foi possível após um longo embate que teve como protagonistas principais os familiares de mortos e desaparecidos e ex-presos políticos que, associados e organizados em entidades, cobravam do Estado brasileiro o reconhecimento e a reparação dos crimes por ele cometidos durante o período ditatorial.

A longa luta para a instituição das diversas comissões da verdade, que chegaram a uma estimativa de quase cem, segundo o relatório final da CNV, reflete o entendimento das vítimas do regime de que o Estado deveria promover políticas de reconhecimento dos abusos e crimes 
cometidos e também gerar mecanismos de prevenção para que a sociedade não fosse mais refém de estados autoritários e de políticas públicas cerceadoras das liberdades. Dessa forma, quanto mais os crimes cometidos durante os regimes de exceções chegassem ao conhecimento público, mais perto estaríamos de evitar a repetição dos erros do passado. Somado a isso, estaríamos também mais próximos do (re)conhecimento de nossa história e, consequentemente, da construção de uma sociedade alicerçada na democracia: "é uma tentativa para esconjurar ou desafiar a reversibilidade dos acontecimentos históricos, colocando (pelo que é humanamente possível) um ponto firme, uma virada de página, um ponto de não-retorno, uma cláusula pétrea no pacto social que funda um Estado Democrático de Direito" (TOSI \& SILVA, 2014, p.45).

No Brasil se tentou forjar uma cultura do esquecimento dos crimes cometidos no período de 1964 a 1985, e foi o próprio governo militar que conduziu a transição democrática promulgando, em 1979, a Lei da Anistia. Uma lei de "duas mãos", conforme a definição de Flávia Piovesan (2010), uma vez que, em nome da reconciliação nacional, igualaram-se em um mesmo patamar as ações praticadas por agentes de Estado no exercício de suas funções e integrantes da sociedade civil. Mais do que isso, essa lei acabou impedindo que esses agentes de Estado fossem levados ao banco dos réus e que fossem julgados culpados pelos crimes cometidos no período. A imposição do esquecimento pelo Estado (como gesto forçado de apagar, de ignorar, de fazer como se os crimes, traumas e sofrimentos não tivessem acontecido) vai justamente na direção oposta às funções positivas do esquecer pela vida. Lembra-nos Cristina Buarque de Hollanda (2018) de que, mesmo com a existência de variantes mecanismos de intervenções, teóricos e operadores da justiça de transição convergem em torno de algo comum: o esclarecimento de crimes passados é condição para sua não repetição.

De acordo com Hollanda (2018), que realizou pesquisas e entrevistas com vários presidentes de subcomissões em atividades espalhadas pelo país, foi a partir da criação da CNV, entre 2012 e 2016, que o Brasil registrou uma proliferação de comissões da verdade, vinculadas aos poderes executivos e legislativos, nos âmbitos estaduais e municipais, bem como comissões criadas por sindicatos, universidades e associações profissionais ${ }^{11}$. Segundo Hollanda, essas comissões locais tiveram seus andamentos e diretrizes apenas em parte acompanhados pela CNV, e esse fenômeno, que chamou de "comissionismo", foi caracterizado pela heterogeneidade e atuação particularizada dessas subcomissões, que combinaram referências metodológicas da CNV com horizontes mais palpáveis, com estruturas semelhantes de menor porte, mas independentes e incentivadas por processos locais.

Uma diferenciação da CNV em relação a essas subcomissões, apontada por Hollanda, teria sido atuações "mais próximas do ponto de vista das vítimas" (HOLLANDA, 2018, p.3). Mais que isso, as comissões locais, segundo ela, contribuíram para a ampliação dos atores afetados pela Ditadura. No lugar do estudante subversivo envolvido com organizações de luta armada nos grandes centros urbanos, essas subcomissões "trouxeram novos personagens - populações indígenas, camponeses, políticos cassados, trabalhadores e servidores públicos - para esse cenário, que correspondem justamente às novas interpretações a respeito do que deve ser considerado graves violações de direitos humanos" (HOLLANDA, 2018, p.11).

Diferentemente do que ocorreu em nível nacional, quando a CEV-AP realizou o trabalho de investigação sobre a Ditadura, poucas pesquisas anteriores e documentos a subsidiaram. Em seu

11 Tal fenômeno ultrapassou a própria iniciativa da CNV, que, em seu relatório final, publicado em dezembro de 2014, sequer foi capaz de identificar o número exato dessas subcomissões, limitando-se a uma estimativa de cerca de cem em todo país. 
relatório final, a Comissão ressalta que a inexistência de um arquivo estadual (ou de qualquer outra natureza) que reunisse a documentação sobre o período foi um empecilho para a realização de uma pesquisa mais aprofundada. Essa é uma das contradições do período quando comparado à realidade local, uma vez que já é consenso que a Ditadura brasileira deixou como sombrio legado o maior acervo documental entre suas congêneres no Cone Sul, reunido, desde 2007, no Centro de Referência das Lutas Políticas no Brasil, denominado "Memórias Reveladas"12. Entretanto, além da abertura e da divulgação tardia desses arquivos, que só se concretizaram de fato com a promulgação da Lei de Acesso a Informações, de 2012, esse acervo não contempla ou parcialmente se refere a fatos ocorridos em território amapaense.

É importante reforçar que umas das práticas do regime ditatorial, como estratégia para impedir que os crimes cometidos no período se tornassem de conhecimento público, foi a destruição maciça de documentos. O que tudo indica é que, no caso do Amapá, essa prática produziu um apagamento que dificulta o levantamento de informações e documentos sobre o que ocorreu na região. Esse fato foi vivenciado por Cláudio Nascimento, um dos depoentes da CEV-AP, que presenciou a queima de arquivos por agentes da Ditadura: "eles fizeram aquele monte e queimaram na nossa frente ali. Nós ficamos ali obrigados a assistir" (NASCIMENTO, 2014, s/p)

O debate feito até aqui nos permite pensar a importância que os trabalhos realizados pela Comissão Estadual da Verdade do Amapá, entre os anos de 2013 a 2017, podem ter nesse processo de busca de memória, verdade e justiça, iniciado tardiamente no Brasil e sentido e experienciado com suas particularidades nos diversos estados brasileiros. Através do Relatório Final, do acervo documental e dos testemunhos das pessoas que foram ouvidas pela equipe da CEV-AP, a qual sistematizou de maneira temática os resultados alcançados em seus quatro anos de pesquisa, é possível vislumbrar possibilidades de pesquisas e suas potencialidades para o ensino de História.

O relatório da CEV-AP apresenta dados que permitem entender as dinâmicas operadas pelo regime em uma sociedade como a da capital amapaense, com uma "população pequena, onde o anonimato era impossível e as relações de vizinhança e afeto eram onipresentes e estruturantes da vida em sociedade" (AMAPÁ, 2017, p.21), bem como as características que a repressão assumiu nessa região, que já experienciava uma estrutura militarizada, anterior à 1964, como Território Federal - a exemplo das intervenções em sindicatos e na imprensa, no movimento estudantil secundarista, nas formas de resistência ao regime e nas perseguições políticas, que resultaram em demissões de servidores públicos, de militares e na cassação de mandatos políticos.

Entre as diversas temáticas tratadas pelo relatório, a da "Operação Engasga", conhecida popularmente como "Engasga-Engasga”, descrita como uma operação militar que, em 1973, "produziu, no imaginário social um medo generalizado, desdobrado em uma aversão ao comunismo, servindo como uma estratégia de controle e consenso" (AMAPÁ, 2017, p.49), talvez seja a que melhor exemplifica como, no Amapá, "O medo foi utilizado como instrumento de controle pelo regime” (AMAPÁ, 2017, p.55). Por ser uma experiência particularizada, é possível perceber, através dessa operação, como a Ditadura atuou na região, além de suscitar um debate entre os alunos e alunas que envolva questões do imaginário social e de possibilidades de ler e/ou ouvir depoimentos de homens e mulheres que vivenciaram esse período a partir de um exemplo da realidade local.

Outra temática interessante apresentada no relatório é a guerrilha do Araguaia e o papel do Amapá como base de apoio do Exército no combate à guerrilha. Nesse item são apresentados indícios de como "O Amapá se inseriu no cenário obscuro de desaparecidos da guerrilha,

12 Ver http://www.memoriasreveladas.gov.br/. 
principalmente, no que concerne à ocultação de cadáveres de guerrilheiros na região do OiapoqueAP, especificamente na vila de Clevelândia do Norte, onde poderia existir um cemitério clandestino" (AMAPÁ, 2017, p.58). É nesse tema que a CEV-AP conseguiu avançar na identificação dos dois soldados mortos durante uma operação contra guerrilheiros na região do Araguaia, como já citado no item anterior.

Um dos aspectos explorados pelo relatório que vemos como um dos temas fundamentais a serem abordados nas escolas é sobre os "Lugares de Memória" da Ditadura brasileira, que vêm ganhando muita visibilidade nos últimos anos. Esses são entendidos como locais onde ocorreram prisões e torturas e que possuem toda uma representação social e simbólica como espaços que permitem problematizar as violências e as dores do período. Os lugares de memória que a comissão do Amapá identificou como tendo sido utilizados pelo regime como centros de prisões e torturas de presos políticos são: a Delegacia do Bairro do Trem, as celas do Palácio do Setentrião e da Polícia Federal, o Quartel do Exército, a Prisão do Beirol, a Central de Polícia, a Delegacia de Investigação e Captura (DIC) e a Fortaleza de São José de Macapá. Dentre eles, o forte de Macapá foi o mais citado nos depoimentos recolhidos pela CEV-AP. Ao se recuperar esse uso de um momento histórico tombado pelo IPHAN desde 1950, como é o caso da Fortaleza de São José de Macapá, como o lugar do cárcere e tortura, rompe-se com o silêncio e esquecimento e se garante, não somente aos amapaenses, mas a todos os brasileiros, o conhecimento do passado que precisa se tornar de conhecimento público, porque compreendemos que nesse processo de lembrar há um pleno exercício de cidadania.

A terceira parte do relatório é dedicada a apresentar o projeto "A memória vai à escola", desenvolvido pela CEV-AP nas instituições de ensino no Amapá (de que trataremos no próximo item); sua parte final é dedicada às recomendações direcionadas ao Poder Executivo. Das quinze recomendações, a que representa um impacto mais direto para a educação escolar é a de número nove, que propõe "incluir no currículo da Educação Fundamental e do Ensino Médio, por meio do plano estadual de Educação, o ensino sobre as violações aos direitos humanos ocorridas na ditadura" (AMAPÁ, 2017, p.78).

Não foi nossa intenção aqui indicar como esse relatório deve ser utilizado nas aulas de História, mas sim apresentá-lo como uma boa possibilidade para se trabalhar a Ditadura a partir de dados e informações coletados localmente. O trabalho da CEV-AP foi realizado, sobretudo, a partir da coleta de testemunhos que podem ser utilizados por professoras e professores como fontes de História Oral. $\mathrm{Na}$ ausência de outros acervos documentais sobre o período, essas fontes orais apresentam-se como solução metodológica importante. Como bem apontado por Danilo Pacheco em "Memórias em sala de aula: uma análise das entrevistas realizadas pela Comissão estadual da Verdade do Amapá e suas potencialidades para o ensino de história”, a utilização desses depoimentos em sala de aula "pode contribuir no sentido de tornar o discente mais sensível ao passado autoritário" (PACHECO, 2020, p.125). Esse artigo de Pacheco, fruto de sua dissertação de mestrado, pode ser citado como um primeiro esforço de pensar, no ensino de História, através do uso dos testemunhos da CEV-AP, como a Ditadura atuou em nível local.

O relatório da Comissão Estadual da verdade pode contribuir no sentido de apresentar as temáticas que foram pesquisadas de maneira sistemática, oferecendo um conjunto de narrativas de pessoas que vivenciaram os impactos da Ditadura em uma perspectiva amapaense. A professora ou o professor que desejar aprofundar qualquer uma dessas temáticas a partir da consulta ao material levantado por essa comissão encontrará, contudo, muitas dificuldades, pois até o presente, o site http:/ /www.cev.ap.gov.br/, que deveria disponibilizar as fontes coletadas, embora ainda esteja 
em funcionamento, não disponibiliza acesso a todas as informações.

\section{Os caminhos da pesquisa e do ensino da Ditadura no Amapá: a expe- riência do GPDD na Unifap}

Como nossos objetivos se limitaram a fazer um balanço do que se tem acumulado sobre a história da Ditadura no Amapá (para assim apontar possibilidades de inflexão sobre esse debate tão necessário), não iremos oferecer uma discussão sobre currículo, formação docente ou material didático. Porém, esses são temas que se encontram imbricados no escopo de nossas preocupações e proposições desenvolvidos dentro do Grupo de Pesquisa Democracias e Ditaduras (GPDD) e são alvos de investigações em projetos de pesquisa e/ou extensão específicos que estamos desenvolvendo. Dessa forma, achamos importante compartilhar também nosso comprometimento com a investigação e a divulgação da temática da Ditadura e demonstrar como a institucionalização de nossas pesquisas foi pensada como estratégia de construção de diálogo da universidade com as demais instituições de ensino do estado.

A criação do GPDD ${ }^{13}$, em 2017, ocorreu logo após a finalização dos trabalhos da CEV$\mathrm{AP}$, com o objetivo de dar continuidade às pesquisas iniciadas pela CEV-AP e de reunir professoras, professores, pesquisadoras, pesquisadores, alunas e alunos, membros da sociedade civil organizada (em movimentos sociais, sindicais, estudantis) e demais profissionais da pesquisa e educação sensibilizados com temáticas que envolvam a difícil consolidação da democracia em países periféricos como o Brasil, que ainda enfrentam a permanência cruel desses processos históricos de colonização, escravidão e autoritarismo dentro de suas estruturas sociais, econômicas, políticas e culturais.

Havia um entendimento compartilhado entre nós, docentes da Unifap que compuseram a CEV-AP, de que se fazia necessário o desenvolvimento de projetos institucionais que garantissem a guarda e a divulgação da documentação recolhida e produzida pela CEV-AP. Em um estado como o Amapá, com grandes dificuldades de acesso à informação e fontes ${ }^{14}$, essa institucionalização foi entendida como tarefa mais urgente. Também se tinha em mente que era preciso garantir a não interrupção do processo de investigações iniciado pela CEV-AP e que, por falta de estrutura e financiamento, não pôde ser realizado durante o período de sua vigência. As duas questões que

\footnotetext{
13 A aprovação do cadastro do Grupo de Pesquisa Democracias e Ditaduras pelo SIGAA da Unifap só ocorreu em 19 de agosto de 20019 (Processo 23125.022951/2019-47).

14 Com intuito de identificar os arquivos referentes à Ditadura Militar mencionados pelas comissões de verdade, Mônica Tenaglia e Georgete Medleg Rodrigues mapearam os relatórios finais dessas comissões que já haviam sido publicados até a data da pesquisa. O fato de o Amapá não possuir um arquivo público estadual e de isso ter sido mencionado pela comissão do Amapá como um dos grandes problemas enfrentados no decorrer das atividades da CEV-AP foi destacado pelas pesquisadoras. Segundo elas: "apesar da própria Constituição Estadual do Amapá instituir como dever do Poder Público a custódia, gestão e disponibilização dos documentos, aquele estado sequer possui um arquivo público" (TENAGLIA \& MEDLEG, 2018, p.290). Em outro trecho as autoras chamam atenção para o fato de que as dificuldades de estrutura e logísticas enfrentadas pela CEV-AP foram enormes e a Unifap acabou se tornando uma parceria fundamental para a realização dos trabalhos: "para enfrentar as dificuldades resultantes da ausência de gestão dos arquivos utilizados, a comissão firmou uma parceria com a Universidade Federal do Amapá (Unifap), que disponibilizou estagiários do curso de História para desenvolver as atividades de transcrição das oitivas, organização do acervo documental e pesquisa sobre dados biográficos" (TENAGLIA \& MEDLEG, 2018, p.290). Para enfrentar as dificuldades resultantes da ausência de gestão dos arquivos utilizados, a comissão firmou uma parceria com a Universidade Federal do Amapá (Unifap), que disponibilizou estagiários do curso de História para desenvolver as atividades de transcrição das oitivas, organização do acervo documental e pesquisa sobre dados biográficos.
} 
foram apontadas no relatório final como prioridades a serem investigadas são os impactos da Ditadura em comunidades indígenas presentes em território amapaense e a denúncia da existência de um cemitério clandestino em Clevelândia do Norte, que teria sido usado pelas forças armadas para o ocultamento de corpos de militantes da Guerrilha do Araguaia ${ }^{15}$. No que se refere à questão indígena, as recomendações da CEV-AP são incisivas:

Um tema que identificamos como imprescindível para o entendimento da especificidade do Amapá, que é o de como a ditadura atingiu de maneira particularmente cruel os povos indígenas da região, ficou completamente fora do escopo de nossas investigações e recomendamos que seja criado um grupo que se dedique à realização de oitivas com lideranças e de pessoas próximas às comunidades indígenas (AMAPÁ, 2017, p.81).

O Relatório Final da CEV-AP representa um instrumento de denúncia dos crimes cometidos pelo Estado brasileiro (por seus agentes e por parcelas da sociedade civil) que perseguiu, estigmatizou, aprisionou e torturou homens e mulheres, no Território Federal do Amapá. A Unifap foi pensada como espaço por excelência para dar continuidade a essas pesquisas e assim garantir que o acervo deixado pela CEV-AP, que ainda carece de tratamento, possa ser ampliado e disponibilizado para pesquisa e, o mais importante, possa chamar atenção para que as recomendações elaboradas por essa comissão sejam continuadas pelas diversas instâncias sociais e públicas.

Dentre as preocupações apontadas pelo GPDD no momento de sua criação, a retomada do Projeto "A Memória Vai à Escola" apresentou-se como uma demanda urgente a ser encarada. Foi no andamento das atividades de investigação sobre a Ditadura na região que a equipe de trabalho da comissão do Amapá, composta em sua grande maioria por professores (universitários e da Educação Básica), decidiu, mesmo em fase de realização de coleta de testemunhos, levar ao espaço escolar e acadêmico o debate sobre a Ditadura Civil-Militar e sobre temas afins, através de parcerias com escolas e universidades do Estado do Amapá.

A experiência de ensino vivenciada pela CEV - AP ainda necessita ser mais bem analisada. Porém, o pretendido neste item foi demonstrar como esse exemplo ajudou a pensar o projeto de extensão em andamento: “A Memória Vai Escola”, que objetiva ofertar formação continuada para professoras e professores da educação básica do Estado do Amapá. O projeto parte do pressuposto de que a universidade deve e pode oferecer instrumentalização, tanto teórica, quanto pedagógica, para que os professores e professoras da Educação Básica possam trabalhar com a temática da Ditadura em suas escolas.

Para esse primeiro momento de desenvolvimento dessa extensão, os materiais de apoio sugeridos foram especificamente os produzidos pela CEV-AP: os testemunhos, o acervo documental e o relatório final. Porém, a percepção dos desafios como pesquisadoras/professoras de se trabalhar com a temática da Ditadura no Amapá nos fez perceber que era necessária a ampliação dos horizontes de pesquisa, através de reflexões sobre ensino e Ditadura que propiciem diálogos entre presente e passado, sobretudo em tempos como estes, marcados pelas incertezas e inseguranças com o futuro.

No mesmo intento, propusemos o projeto de pesquisa "Ditadura e ensino de História no tempo presente", direcionado a investigar o ensino da Ditadura Civil-Militar a partir do caso do

\footnotetext{
15 Essa denúncia foi levantada em oitiva por um dos testemunhos da CEV-AP. A pedido, a identidade do depoente foi mantida sob sigilo e seu depoimento foi colhido no prédio do Ministério Público Federal, com a participação do Procurador Geral.
} 
Amapá. O projeto foi pensado a partir de um recorte temporal que considera os usos do passado que são feitos no presente sobre essa temática, tendo em vista o papel que o ensino pode e deve exercer nessa relação. Conforme analisou Ana Kallás (2015), usos de métodos similares aos utilizados ao longo do regime ditatorial brasileiro, como execução sumária, tortura, desaparecimento forçado e prisões arbitrárias infelizmente ainda são observados em acontecimentos recentes, exemplificados por ela em eventos ligados em sua maioria à cidade que pesquisa, o Rio de Janeiro. Nosso objetivo é similar: pensar nessas continuidades como forma de se trabalhar o ensino da Ditadura, mas a partir de fatos recentes vividos na cidade Macapá, capital do Amapá.

Trabalhar com acontecimentos recentes para se compreender a Ditadura Civil-Militar não é uma tarefa fácil. Exige também uma aproximação com as teorias e metodologias da História do tempo presente, campo de estudo que, apesar de estar em crescimento no Brasil, ainda encontra resistência entre historiadoras e historiadores que defendem o distanciamento com o presente como garantia para se produzir história (FERREIRA \& DELGADO, 2003). Como aponta Kallás (2017, p.8), apesar de a história se retroalimentar da memória e de até, algumas vezes, confundirse com ela, a memória não é história e

O ensino de história não é constituído apenas por recordações de eventos passados e pelo esquecimento de outros tantos. A história, além de recordação, é uma prática epistêmica disciplinada, que produz uma forma de conhecimento com pretensões de verdade e se utiliza de métodos racionais de investigação, análise, crítica e escrita.

Os projetos desenvolvidos no GPDD/UNIFAP têm, no momento, como preocupação central, compreender a urgência no ensino do tema da Ditadura Civil-Militar, como já enfatizado, e pensar a necessidade de discussão dessa temática a partir da História do tempo presente e do ensino de história local. Conforme Marcos Silva (2016), a totalidade de jovens e adultos não chegam à sala de aula com memórias diretas do período ditatorial, uma vez que não vivenciaram essa época. Entretanto, carregam migalhas de cultura histórica sobre o tema, construídas em diversos canais de informações, como filmes, telenovelas, discursos políticos, textos de imprensa e literários etc., que abrigam reflexões com cargas ideológicas que podem ser preocupantes, como as visões fantasiosas sobre o período, as quais defendem que os problemas atuais em saúde, moradia e educação não existiam na época da Ditadura ou que a violência autoritária é melhor do que as inseguranças democráticas: "qualquer currículo de história do Brasil, destinado a diferentes faixas etárias e níveis de ensino, deve contemplar a experiência dessa ditadura como importante tema do século XX e como problemática de conhecimento digna de muita atenção (SILVA, 2016, posição 906)".

A esse rol de espaços em que estudantes se formam ao longo de sua trajetória, entendemos ser de vital importância destacar o papel que as mídias sociais têm em suas existências, até para pensar com quais argumentos e informações ou desinformações iremos dialogar no momento de confrontar esse imaginário social com os resultados da pesquisa histórica e o que que está se querendo ensinar sobre essa temática. Ou seja, o aluno e a aluna carregam consigo muitas informações sobre o tema que circulam, na maioria das vezes, em espaços nos quais os limites entre o que se anuncia e o que de fato ocorreu são extremamente fluídos.

Cabe ao professor e à professora saber dialogar com essas armadilhas reconhecendo qual seu papel nesse processo. Ao resolver incluir a Ditadura em planos de ensino e/ou em projetos na educação básica, uma série de dificuldades se apresenta, pois tratar de um tema como esse, de difícil reflexão e incursão, e que levanta tantos debates públicos no presente, é uma tarefa 
demasiadamente complexa. Em tempos de projetos de Lei como o "Escola sem partido", acreditamos que a institucionalização de projetos de formação continuada e inicial seja uma salvaguarda para esses profissionais.

Refletir sobre esse passado a partir de uma relação com o presente é fundamental para que as novas gerações, que não vivenciaram aquela época, possam fazer escolhas informadas pelo conhecimento histórico. Como o papel de educar está diretamente relacionado ao país que queremos, queremos contribuir com os esforços de educadores e educadoras que buscam oferecer a seus estudantes conhecimento histórico acerca do que ocorreu nesse período e de como se deu o duro processo de retorno democrático. Devemos aprender e ensinar pela formação de uma consciência crítica em torno das graves violações aos direitos das pessoas, pelo apreço às liberdades e pela certeza de que é preciso cuidar para que o autoritarismo diminua cada vez mais em nossa sociedade. Por isso, ressaltamos o quão imprescindível é a aliança entre pesquisa e ensino como instrumento para a construção um estado de fato democrático no Brasil.

\section{Considerações Finais}

Como já explicitado neste artigo, foi nossa pretensão promover uma reflexão acerca do ensino de História da Ditadura Civil-Militar no Amapá (a partir do levantamento de pesquisas científicas e de fontes sobre o período), apontando os dilemas e as possibilidades abertas para o ensino dessa disciplina em nível local. Nossa intenção foi chamar a atenção para a necessidade de que se desenvolvam novas pesquisas sobre a temática, mas, sobretudo, da construção de políticas institucionais que permitam que professoras e professores das redes públicas tenham acesso à documentação primária e secundária sobre a Ditadura no Estado, para que, assim, o senso comum de que no Amapá não houve Ditadura (ou que defende que ela foi benéfica para o desenvolvimento econômico e urbanístico da região) possa ser refutado a partir da produção e do acúmulo historiográfico sobre o tema. Foi nossa intenção contribuir para um debate que considere esse tema como um dos pilares articulantes do ensino de História, dentro de um contexto mais amplo de políticas públicas voltadas para a manutenção da democracia.

Não há como ignorar um efervescente movimento na atualidade de renovação das discussões e disputas sobre o que foi e o que representou a Ditadura. A emergência do tema e a eclosão de movimentos de defesa do regime podem ser entendidos como resultantes do processo inacabado e tardio no Brasil de políticas públicas no sentido de justiça de transição, e têm provocado, sobretudo, em razão dos acontecimentos políticos recentes, a exposição das feridas sociais ainda não cicatrizadas. Acreditamos que o avivamento do tema se deve, em grande parte, aos impactos duradouros e ainda visíveis de uma cultura autoritária que ainda insiste em impregnar as relações sociais, traduzida na democratização incompleta de Estado e Sociedade. Assim, discutir as possibilidades para o ensino de História da Ditadura e contribuir com esforços para que esse seja pensado para além dos limites das atuações individuais de docentes foram os principais pontos de investigação apresentados neste artigo. As possibilidades de que educadoras e educadores possam apresentar às gerações mais jovens um arcabouço de dados e análises históricas capazes de confrontar o entendimento baseado no negacionismo cada vez mais socialmente compartilhado sobre a Ditadura são caminhos promissores que se abrem a partir da pesquisa e do ensino.

Mesmo que não tenha sido o objeto direto deste artigo inquirir sobre como a Ditadura é abordada nas escolas do Amapá atualmente, chamamos atenção para a realização de pesquisas 
nesse sentido, pois isso significa entender as intrincadas redes que envolvem as pessoas que constroem na prática a educação. Perceber as relações entre diversos graus de ensino - as escolas e a Unifap, por exemplo, é pensar no currículo e na formação inicial da licenciatura em História, bem como nos programas de formação continuada que devem ser ofertados por instituições ou pelo Estado (na esfera nacional, estadual ou municipal). Mais do que isso, é pensar nos projetos políticos-pedagógicos das escolas e nos projetos desenvolvidos por grupos de docentes ou individualmente por professoras e professores de escolas específicas.

Encerramos este artigo, infelizmente, com a constatação de que a imagem impactante do aluno de História defendendo a Ditadura não é um caso isolado, como também não é o único exemplo que podemos citar em um universo assustador de declarações que, com essa, dizem muito da sociedade em que vivemos. Para Verena Alberti, nós professoras e professores estamos vivendo momentos que talvez nunca imaginássemos viver. Além dos ataques que sofremos, "não são poucas as notícias de alunos e alunas que se digladiam, usando-se muitas vezes o refúgio das redes sociais [...]. Acusações mútuas de "comunista" e de "fascista, sem passar pelo diálogo, proliferam" (ALBERTI, 2020, p.109). Como bem nos alerta Alberti, não devemos nos esquecer de que "a escola está dentro da sociedade e não é diferente dela, por isso mesmo estamos vivendo essas situações, em uma reprodução do que acontece em outras situações da vida social". Sigamos!

\section{Referências}

ABRÃO, Paulo. Educar para o futuro. In: ARAÚJO, Maria Paula; SILVA, Izabel Pimentel da; SANTOS, Desirree dos Reis. Ditadura militar e democracia no Brasil: história, imagem e testemunho. Rio de Janeiro: Ponteio, 2013, p.7.

ALBERTI, Verena. Cultura política, história e ensino. In: MENESES (org.). História, Memórias e Direitos. São Paulo: Letra e Voz, 2019, p.99-112.

AMAPÁ. Relatório final da Comissão Estadual da Verdade do Amapá. Macapá: SECOM, 2017.

AMARAL, Alexandre et al. (Orgs.). Do lado de cá: fragmentos de História do Amapá. Belém: Açaí, 2011.

ARAÚJO, Maria Paula. O Ensino da Ditadura Militar nas Escolas: Problemas e Propostas de Trabalho In: ARAÚJO, Maria Paula; SILVA, Izabel Pimentel da; SANTOS, Desirree dos Reis. Ditadura militar e democracia no Brasil: história, imagem e testemunho. Rio de Janeiro: Ponteio, 2013, p. 10-11.

ARENDT, Hannah. Eichmann em Jerusalém - Um relato sobre a banalidade do mal. Tradução de José Rubens Siqueira. São Paulo: Companhia da Letras, 1999.

BAUER, Caroline Silveira. Posfácio: Democracia, ditadura, tempo presente. In: DAHÁS, Nashia; RIBERT, Larissa; JOFFILY, Mariana (Orgs). 1968: perspectiva desde o tempo presente. São Paulo: Letra e Voz, 2020, p.227-233.

BRASIL. Presidência da República. Casa Civil. Subchefia para Assuntos Jurídicos. Lei $n^{\circ} 12.528$, de 18 de novembro de 2011. Cria a Comissão Nacional da Verdade no âmbito da Casa Civil da Presidência da República. Disponível em: http://www.planalto.gov.br/ccivil_03/_ato20112014/2011/lei/I12528.htm\#: :text=Cria\%20a\%20Comiss\%C3\%A3o\%20Nacional\%20da,Art.

Acesso em 21 nov. 2020.

FICO, Carlos. Ditadura militar: prefácios, palestras \& posts. Formato eBook Kindle, 2020.

KALLÁS, Ana Lima. Ditadura e redemocratização do Ensino de História: revisitação a partir de eventos recentes. Anais Eletrônicos do XXVIII Simpósio Nacional de História - lugares dos historiadores: velhos e novos desafios. De 27 a 31 de julho de 2015, Florianópolis-SC.

HOLLANDA, Cristina Buarque de. Direitos Humanos e Democracia. A experiência das Comissões da Verdade no Brasil. Revista Brasileira De Ciências Sociais. Vol. 33, N. 96, 2018. 
LOBATO, Sidney. O Espetáculo da Ordem: paradas estudantis amapaenses em tempos de ditadura (1967-1972). In: FRANÇA, Maria do Perpétuo et al. (Orgs). História da Educação na Amazônia: múltiplos sujeitos e práticas educativas. Curitiba: CRV, 2018, p.143-162.

LOBATO, Sidney. Os Empresários e a Amazônia: planejamento regional e protagonismo empresarial no início da ditadura militar (1964-1966). In: REIS, Tiago Siqueira et al. (Orgs). Coleção história do tempo presente: vol. 3. Boa Vista: Editora da UFRR, 2020, p.92-115.

MAUAD, Ana Maria et al. (Orgs). História Pública no Brasil: sentidos e itinerários. São Paulo: Letra e Voz, 2016.

NASCIMENTO, Cláudio. Depoimento de 28 de agosto de 2014. Acervo CEV-AP. Centro de Memória, Documentação Histórica e Arquivo/ UNIFAP.

NETO CARDOSO, João Francisco. Depoimento de 24 de novembro de 2014. Acervo CEV-AP. Centro de Memória, Documentação Histórica e Arquivo/ UNIFAP.

PACHECO, Danilo Mateus da Silva. 150f. Tempo de Lembrar: Memórias da Ditadura e Ensino de História do Amapá. Dissertação. Mestrado em História (ProfHistória), Universidade Federal do Amapá Macapá, 2018.

PIMENTEL, Walbi. A Igreja dos Pobres no Amapá: solidariedade, resistência e conflito (1966- 1983). Anais eletrônicos do III Encontro de Discentes de História da UNIFAP. De 22 a 25 de agosto de 2017 - Macapá- AP.

PIOVESAN, Flávia. Direito Internacional dos direitos humanos e lei de anistia: o caso brasileiro. In: TELES, Edson; SAFATLE, Vladimir (orgs). O que resta da ditadura. São Paulo: Boitempo, 2010, p.91107.

SILVA, Giovani José da \& ROCHA, Anderson. História, Ambiente e Povos Indígenas no Extremo Norte do Brasil: Impactos da Construção da BR-156 em Oiapoque, Amapá (1976-1981). História Unicap, v. 6, n. 12, jul./dez. de 2019.

SILVA, Marcos. Aprender a ditadura brasileira de 1964-1985. Ensino de história depois da casa da morte. In: GUIMARÂES, Selva. Ensino de História e Cidadania. Papirus Editora, 2016, p.232-248. Formato eBook Kindle.

SILVA, Maura Leal da. O Território imaginado: Amapá, de território à autonomia política (19431988). Tese (Doutorado em História). Programa de Pós-Graduação em História. Brasília-DF: Universidade de Brasília, 2017.

SILVA, Maura Leal da. O Território do Terror: agitações, prisões e repressões no alvorecer do golpe civil-militar no Amapá. Anais eletrônicos do Seminário 1964-2014: um olhar crítico, para não esquecer. Belo Horizonte -MG, de 18 a 20 de março de 2014, p.347-357.

SILVA, Maura Leal da. A Ditadura da liberdade. Um Brasil que 64 não revelou. Anais eletrônicos do XXVII Simpósio Nacional de História - Conhecimento histórico e diálogo social. Natal-RN, de 22 a 26 de julho de 2013.

TENAGLIA, Mônica \& RODRIGUES, Georgete Medleg. As recomendações das comissões da verdade no Brasil sobre os arquivos da ditadura militar (1964-1985): uma análise dos relatórios finais. Em Questão, Porto Alegre, v. 24, n. 2, p. 280-299, maio/ago. 2018. DOI: http://dx.doi.org/10.19132/1808-5245242.280-299.

TOSI, Giuseppe et al. (Orgs.). Justiça de transição: direito à justiça, à memória e à verdade. João Pessoa: Editora da UFPB, 2014. 